\title{
How logical is safety? An institutional logics perspective on safety at work
}

\author{
Pieter A. Cornelissen*, Mark Van Vuuren and Joris J. Van Hoof \\ Department of Communication Science, Faculty of Behavioural, Management and Social Sciences, \\ University of Twente, Enschede, The Netherlands
}

Received 15 August 2018

Accepted 11 June 2019

\begin{abstract}
.
BACKGROUND: Occupational incidents and accidents are still commonplace in the contemporary workplace, despite increased understandings of safety.

OBJECTIVE: This article aims to yield new insights into safety-related thinking, decisions and behaviours through the application of an institutional logics perspective.

METHOD: Semi-structured interviews with twenty-two managers in a railroad construction and maintenance organisation were conducted, in which a variety of topics related to occupational safety and management were discussed.

RESULTS: The results illustrate that an institutional logics perspective provides useful insights into the different logics of the market, profession, and corporation in the occupational safety context. Furthermore, the results demonstrate contradictory viewpoints, so-called complexity, between these three logics and subsequent management approaches.

CONCLUSIONS: We demonstrate that viewing occupational safety through the lens of institutional logics leads to a better understanding of safety and reveals various rationales for safety attitudes and behaviours that otherwise may have been dismissed as irrational. Understanding and possessing the discourse of logics can help managers and safety professionals with analysis and prevention of accidents.
\end{abstract}

Keywords: Workplace safety, institutional complexity, market logic, profession logic, corporation logic

\section{Introduction}

Occupational accidents are still commonplace in contemporary workplaces, despite increased understanding of safety, human psychology, and human-technology interaction [1-3]. Researchers and practitioners not only struggle to understand, reduce and prevent occupational accidents but also seemingly view such events as a result of irrational behaviours and decisions [4]. However, dismissing behaviour as irrational is "simply an admission that the behaviour is inexplicable in terms of the concepts to hand' [4, p148], which subsequently makes

\footnotetext{
*Address for correspondence: Pieter Cornelissen, Faculty of Behavioural, Management and Social Sciences, University of Twente, PO Box 217, 7500 AE, Enschede, the Netherlands. E-mail: p.a.cornelissen@utwente.nl.
}

it difficult to develop policies and interventions to counter (unsafe) behaviour. In the present study, we propose that the perspective of institutional logics [5-7] can be used to uncover, illustrate, and explain dynamics that are overlooked by traditional methods of studying occupational safety. We have three aims with this introduction of logics in the safety context. First, to reveal the different logics at play when safety is discussed. The multiplicity of logics and their settlement in organisations enables us to better understand why occupational safety often fails. Second, to explain how employees apply different logics and thereby differ in terms of their approach to occupational safety, which can be traced by seeing how they explicitly articulate their logic. Third, to increase current understandings of the various logics in order to help find solutions that minimise the amount of 
conflict within organisations, which depends on the manners in which the multiple logics are treated in a given situation.

\section{Theoretical framework}

Behaviours and decisions at a given moment are based on the knowledge, perspective and understanding people have of the situation at that time, something that is called 'local rationality' [8]. Viewing occupational safety issues through the lens of different institutional logics provides a pragmatic avenue for identifying such local rationalities and analysing the complexities associated with them, as there are distinct logics present in organisational contexts that each provide their own coherent rationale for safety [9].

Institutional logics are 'the socially constructed, historical patterns of material practices, assumptions, values, beliefs, and rules by which individuals produce and reproduce their material subsistence, organize time and space, and provide meaning to their social reality' [10, p804]. Greenwood et al. [6, p318] summarise the content of this pattern by describing how institutional logics 'provide guidelines on how to interpret and function in social situations'. Such institutional logics define what is considered valuable within a cultural system [5, p232] and what is considered the most rational choice to make. Combined, these cultural systems, or institutional orders, 'compose the key cornerstone institutions of society' [7, p53]. Logics are the more subtle and abstract underlying mechanisms that guide institutional orders and social meaning [11]. A logic ultimately comes down to the root metaphors that people use to view reality [5]. This creates a coherent logic as people define rationality from a certain perspective. The use of an institutional logics approach thus allows for the explanation of behaviour beyond the assumption that people think alike about the consequences of working unsafely. Depending on the specific dominant logic, people will differ in their assessment of what is (in)appropriate, (ir)rational, and (un)safe in the safety context.

The most widely accepted set of ideal types of institutional logics, which we therefore also apply in the present study, was proposed by Thornton et al. [7]. This set comprises seven institutional orders: the market, the profession, the corporation, the state, the family, the community, and the religion. Each of these orders has its own distinct logic that provide guide- lines for the interpretation and functioning in social situations [6, p318]. This set of logics has proved effective in a variety of studies [cf. 12-14]. The institutional logic forms the basic unit, and field logics, organisation logics, and individual logics emerge from there and are 'nested within these societal-level logics' [15, p366]. We will summarise each of the orders and their application to the safety context (see Table 1).

\subsection{Multiplicity of logics}

Within organisations stakeholders rarely consider the same set of values, beliefs, rules and behaviours as rational. As organisations strive for stability and external support they incorporate a variety of incompatible structural elements [16, p356] often leading to the presence of multiple logics $[6,15]$. Such multiplicity of logics can lead to confusion and tension [17], because the participants in the interaction do not share the same set of values, definition of rationality and reality. A typical example of such a clash between logics can be found in the field of healthcare, in which the logics of the market and the profession collide [18, p199].

Whereas early work about logic multiplicity framed the relationship between conflicting logics in terms of dominance [18], later research associated logic multiplicity with increased durability, sustainability, and innovativeness [15]. Additionally, research found that multiple conflicting logics can coexist for long periods of time or remain unresolved [18], and identified organisations that could not achieve their goals with one singular logic [11]. In order to account for these conflicting outcomes of logic multiplicity research, Besharov and Smith [15] developed a framework that allows for the categorisation of organisations along two (continues) axes: the degree of logic compatibility (i.e., the extent to which logics provide (in)compatible prescriptions for action) and the degree of logic centrality (i.e., the extent to which one or multiple logics are core to organisational functioning). On the outer edges of these axes, Besharov and Smith [15, p371-373] identify four ideal types of organisations incorporating multiple logics: (1) contested organisations, (2) estranged organisations, (3) aligned organisations, and (4) dominant organisations. With their framework, Besharov and Smith [15] focus on the implications of logic multiplicity for internal conflict, as it is a central concern in previous research about logic multiplicity. 
Table 1

An overview of key references, the defining characteristics of the seven interinstitutional orders, and their application to safety

\begin{tabular}{|c|c|c|c|}
\hline Logic & Summary & $\begin{array}{l}\text { Defining characteristics for } \\
\text { rationality }\end{array}$ & $\begin{array}{l}\text { Application to occupational } \\
\text { safety }\end{array}$ \\
\hline Market order & $\begin{array}{l}\text { Within the order of the market, the } \\
\text { focus is on 'the accumulation, } \\
\text { codification, and pricing of human } \\
\text { activity' [7,p44]. Central to the } \\
\text { market logic is that efficiency } \\
\text { underlies profitability, business } \\
\text { practices are determined by the } \\
\text { maximum value possible from } \\
\text { transactions, and firm reputation is } \\
\text { based on success in the market [27]. } \\
\text { The influence of the market logic is } \\
\text { exemplified in critics' reviews of a } \\
\text { symphony orchestra [28]. }\end{array}$ & $\begin{array}{l}\text { - Priority is given to } \\
\text { (consumer) choice, quality } \\
\text { and profit. } \\
\text { - Values are competition and } \\
\text { customer preference. } \\
\text { - Success is a larger share } \\
\text { and profit. }\end{array}$ & $\begin{array}{l}\text { Safety is considered an asset } \\
\text { for gaining market share. } \\
\text { Although safety might } \\
\text { decrease efficiency, } \\
\text { securing it might outweigh } \\
\text { the costs associated with } \\
\text { incidents, accidents, and } \\
\text { (lost time) injuries, and can } \\
\text { give the organisation an } \\
\text { advantage in consumer } \\
\text { choice. }\end{array}$ \\
\hline Profession order & $\begin{array}{l}\text { Within the order of the profession, } \\
\text { individual members form organised } \\
\text { bodies who 'create knowledge and } \\
\text { belief systems that define arenas of } \\
\text { interest and jurisdiction' [29, p83]. } \\
\text { The basis for autonomy and } \\
\text { authority of professionals stems } \\
\text { from the legitimacy of a mission and } \\
\text { the professionals' 'exclusive ability } \\
\text { to apply expert and esoteric } \\
\text { knowledge to particular cases' [29, } \\
\text { p83]. The organisation structure of } \\
\text { the professional is based on } \\
\text { individual relations. As such, it is } \\
\text { often viewed as antithetical to the } \\
\text { hierarchical means of control of } \\
\text { corporations [29]. The logic of the } \\
\text { profession has been exemplified in } \\
\text { written pitches of architecture firms } \\
\text { [30]. }\end{array}$ & $\begin{array}{l}\text { - Priority is given to the } \\
\text { opinion of credible } \\
\text { members of a professional } \\
\text { community. } \\
\text { - Values are membership, } \\
\text { expertise, training, and } \\
\text { mentoring. } \\
\text { - Success is a product of high } \\
\text { quality provided by } \\
\text { professionals, socialised } \\
\text { within their community. }\end{array}$ & $\begin{array}{l}\text { Safety is left to the discretion } \\
\text { of the professional who is } \\
\text { thought to have the } \\
\text { knowledge and ability to } \\
\text { make skilled independent } \\
\text { judgements of situations. } \\
\text { In extremis, safety is left to } \\
\text { expert safety managers. }\end{array}$ \\
\hline Corporation order & $\begin{array}{l}\text { The order of the corporation is centred } \\
\text { around the organisational structure } \\
\text { of the organisation with its } \\
\text { hierarchical levels. Its sources of } \\
\text { legitimacy stem from the market } \\
\text { position of the firm, and authority is } \\
\text { exercised by the board of directors } \\
\text { and top management. The influence } \\
\text { of the logic of the corporation was } \\
\text { exemplified in a study on the higher } \\
\text { education publishing industry [10]. }\end{array}$ & $\begin{array}{l}\text { - Priority is given to } \\
\text { predictability and } \\
\text { compliance to those higher } \\
\text { in the hierarchy. } \\
\text { - Values are hierarchy, } \\
\text { control and routines. } \\
\text { - Success is following } \\
\text { routines that are defined } \\
\text { within the corporation and } \\
\text { increased hierarchical } \\
\text { status. }\end{array}$ & $\begin{array}{l}\text { Safety is secured through } \\
\text { following rules and } \\
\text { procedures. Compliance } \\
\text { with rules and procedures } \\
\text { is controlled top-down by } \\
\text { managers through } \\
\text { hierarchical and formal } \\
\text { structures. The hierarchical } \\
\text { nature of the corporation } \\
\text { also entrusts managers } \\
\text { with a responsibility they } \\
\text { have to take. } \\
\end{array}$ \\
\hline State order & $\begin{array}{l}\text { The focus in the institutional order of } \\
\text { the state is on converting 'diverse } \\
\text { issues into consensus or majority } \\
\text { vote' to increase community good } \\
\text { [7, p44]. Its source of legitimacy } \\
\text { stems from democratic participation } \\
\text { and authority is exercised through } \\
\text { bureaucratic domination [7]. The } \\
\text { influence of the state logic has been } \\
\text { exemplified in studies on young } \\
\text { firms and innovation [31]. }\end{array}$ & $\begin{array}{l}\text { Priority is given to } \\
\text { deliberation and following } \\
\text { the rules that come from } \\
\text { voting. } \\
\text { - Values are debate and } \\
\text { consensus, democracy, and } \\
\text { rules. } \\
\text { - Success is predictability } \\
\text { from rules, defined and } \\
\text { followed by committed } \\
\text { people. }\end{array}$ & $\begin{array}{l}\text { Safety is secured through } \\
\text { legislation, designed and } \\
\text { imposed by } \\
\text { (representatives of) the } \\
\text { state who are elected } \\
\text { through democratic } \\
\text { majority. }\end{array}$ \\
\hline
\end{tabular}


Table 1

(Continued)

\begin{tabular}{|c|c|c|c|}
\hline Logic & Summary & $\begin{array}{l}\text { Defining characteristics for } \\
\text { rationality }\end{array}$ & $\begin{array}{l}\text { Application to occupational } \\
\text { safety }\end{array}$ \\
\hline Family order & $\begin{array}{l}\text { Within the institutional order of the } \\
\text { family the focus is on 'converting } \\
\text { social relations into reciprocal and } \\
\text { unconditional obligations oriented to } \\
\text { the reproduction of family members' } \\
\text { and 'beliefs are reinforced through } \\
\text { rituals' [7, p44]. In the family logic, } \\
\text { an 'unconditional loyalty to family } \\
\text { underlies business practices', the } \\
\text { firm's identity relies on the family } \\
\text { reputation, and status within the firm } \\
\text { is determined by family membership } \\
\text { [27, p8]. The family logic is } \\
\text { exemplified in Japanese corporate } \\
\text { networks and Japanese management } \\
\text { practices [32]. }\end{array}$ & $\begin{array}{l}\text { - Priority is given to } \\
\text { obligation to the family. } \\
\text { - Values are closeness, } \\
\text { warmth, caretaking, } \\
\text { obligation. } \\
\text { - Success is following } \\
\text { established rituals and } \\
\text { taking care of each other, } \\
\text { and continuation of the } \\
\text { family line. }\end{array}$ & $\begin{array}{l}\text { Safety is important for the } \\
\text { continuation of the family. } \\
\text { Safety is secured through } \\
\text { orders that are based on } \\
\text { established rituals and } \\
\text { tradition, irrespective of } \\
\text { changes in society. }\end{array}$ \\
\hline Community order & $\begin{array}{l}\text { Communities are created through } \\
\text { common boundaries or territories } \\
\text { that create common goals }[7,27] \text {. } \\
\text { Within the order of the community, } \\
\text { actions are driven by emotional } \\
\text { connections between participants, } \\
\text { and cooperative actions should } \\
\text { benefit all [27], not just the } \\
\text { 'common economic needs of the } \\
\text { communal economy' [7, p68]. The } \\
\text { community logic is exemplified in } \\
\text { research regarding activists' protests } \\
\text { aiming to protect local business } \\
\text { communities from chain stores [33, } \\
\text { 34]. }\end{array}$ & $\begin{array}{l}\text { - Priority is given to a good } \\
\text { balance between social and } \\
\text { economic aspects of work. } \\
\text { - Values are community, } \\
\text { balancing, deliberation. } \\
\text { - Success is collaboration and } \\
\text { welfare. }\end{array}$ & $\begin{array}{l}\text { Safety is considered a } \\
\text { communal good and is } \\
\text { accomplished through } \\
\text { taking care of your fellow } \\
\text { members. }\end{array}$ \\
\hline Religion order & $\begin{array}{l}\text { Initially the order of the religion was } \\
\text { described as being centred around } \\
\text { truth, similar to science [5]. } \\
\text { Following critique, Friedland later } \\
\text { states that 'the institutional logic of } \\
\text { the religion centres on the order of } \\
\text { creation, locating humanness in the } \\
\text { cosmos, replicating cosmology } \\
\text { through ritual, a practical } \\
\text { metaphysics that necessarily points } \\
\text { before life and after death' [35, } \\
\text { p134]. This notion is also more in } \\
\text { line with the definition by Thornton } \\
\text { et al. [7, p44], who state that the } \\
\text { order of the religion focuses on 'an } \\
\text { explanation of the origin of the } \\
\text { world and in converting all issues } \\
\text { into expression of absolute moral } \\
\text { principles on the basis of faith'. The } \\
\text { logic of the religion is exemplified in } \\
\text { Friedland's essay about religious } \\
\text { nationalism [36]. }\end{array}$ & $\begin{array}{l}\text { - Priority is given to } \\
\text { submission to faith. } \\
\text { - Values are obedience, } \\
\text { morality, and the order of } \\
\text { creation. } \\
\text { - Success is harmony with } \\
\text { the creator. }\end{array}$ & $\begin{array}{l}\text { Safety is best guaranteed } \\
\text { when following the } \\
\text { exegesis of the faith but is } \\
\text { rooted in the acceptance of } \\
\text { fate (i.e., when it costs, it } \\
\text { costs). }\end{array}$ \\
\hline
\end{tabular}




\subsection{Applying logics to occupational safety}

We propose that an institutional logics perspective provides new methods to uncover, illustrate, and explain the rationale(s) underlying safety-related thinking, decisions and behaviours and that awareness, acknowledgement, and understanding of these different rationales can further improve workplace safety and are much needed to do so.

Institutional logics 'provide guidelines on how to interpret and function in social situations' [6, p318], defining what is considered valuable within a cultural system [5] and what is viewed as the rational choice. As such, occupational safety should not be viewed as a distinct logic, although logics on different levels (e.g., institutional, field and organisational) can be used to explore and explain occupational safety (related) issues [cf. 20-24]. As different logics presume different ideas about safety, and uncovering those different ideas provide insights into what makes safety so difficult to address, their identification and interpretation can help create safer workplaces. Viewing existing research through an institutional logics lens reveals that others have already implicitly illustrated the presence of the state [25, p1001], religious [25, p1001], market [4, p146], and corporate [26, p416] logic in the occupational safety context, as well as implicit illustrations of opposing logics [25, p1002]. An overview of the defining characteristics for rationality and an application to occupational safety of the institutional orders can be found in Table 1 . To explore and illustrate the applicability of logics to the safety context, we analysed data from an organisation in which safety issues arose due to different logics.

\section{Method}

The data reported in this manuscript were collected as part of a larger project regarding the role of occupational safety in managers' work. In the current analyses and report, the focus is exclusively on data concerning institutional logics and logic multiplicity in the occupational safety context.

\subsection{Participants}

Face to face interviews were conducted with supervisors employed at an organisation where occupational safety plays a prominent role in the planning and execution of work (railroad construction and maintenance). Supervisors were explicitly targeted, as they are seen as 'the primary carriers of the contending conceptions of control' [9, p102], are likely to have the power 'to determine organizational responses to multiple institutional logics' [6, p344], and play an increasingly important role in the delegation of job tasks, management of subordinate performance, and balancing competing production, quality, and safety demands [37].

Making use of a stratified sampling technique $(N=30)$ managers were approached to take part in the study. An employee satisfaction survey conducted earlier within the organisation inventoried employees' willingness to participate in safetyrelated follow-up research. From those employees willing to participate in additional research, a selection was made by the HR manager that mirrored the managerial structure of the organisation. Potential participants were first approached via e-mail, of which 22 participated in the study (response rate of $73 \%$ ). All participants were male and at least 40 years old $(M=51.7, S D=5.3)$. Participants' tenure with the current company ranged from 3 to 37 years $(M=18.8$, $S D=9.1$ ), and their overall tenure in the railroad construction and maintenance industry ranged from 3 to 38 years $(M=24.1, S D=9.4)$.

\subsection{Instrument}

Qualitative methods are widely used and have much potential for studying institutional logics [38]. Data were therefore collected via interviews held in offices located at or nearby work locations, and all interviews were recorded with a digital voice recorder with consent. The semi-structured interviews covered themes related to participants' work (e.g., 'Can you tell me about the day-to-day activities in your work?' and 'How many people do you supervise?'), the role of safety in their work (e.g., 'How does safety play a role in your work?') and potential conflicting demands between safety and other organisational demands (e.g., 'Do you ever experience tensions between safety and other organisational demands?' and 'Does it ever happen that other demands get prioritised over occupational safety?'). The interviews lasted between 40 and 96 minutes, with an average duration of 62 minutes.

\subsection{Data analysis}

The recordings were transcribed verbatim and subsequently coded using the ATLAS.ti software 
package (version 7.5). We used a deductive multi-step content-analytic procedure to analyse the data.

First, the first author read the transcripts and marked meaningful units of analyses consisting of single or multiple sentences. Second, this author took the lead in proposing a categorisation of the units of analyses into the institutional orders. Here, a single unit of analysis could reflect a singular logic or be reflective of logic multiplicity. Third, the proposed categorisation was discussed in iterative rounds with the entire research team, linked to the theory, and modified until agreement about the interpretation of each of the different units of analyses was reached. Three logics were found to be most prominently present: the logics of the market (26 quotes by 11 interviewees), the profession ( 34 quotes by 16 interviewees), and the corporation ( 28 quotes by 12 interviewees). Additionally, six quotes that reflected the state logic and one quote that reflected the community logic were found. There were no quotes that reflected the logics of the family or religion, which is in line with earlier findings from Johansen and Waldorf [11] that the state, market, profession, and corporation orders are mainstream organisationalcapitalist orders.

As we searched for strong patterns of institutional logics in the data, the decision was made to exclude statements referring to the community and state logics. For the community logic, this was done because there was only one reference present in the data (i.e., 'And, that is why I say [ ... ] you go out with the four of you, and all four of you have to feel responsible. Because then you can get the job done. And, they also have to help each other because otherwise things are not going well.' - M10). For the state logic, this was done because there were only six references present in the data. Additionally, in discussing this categorisation, it proved difficult to interpret the references to the state logic unequivocally due to uncertainty about the origins of certain rules and regulations (i.e., state or corporation). For example, one interviewee stated that 'officially', he was not allowed to walk from the level crossing to the workplace without the presence of a 'safety man'. From this quote, it is not clear whether 'officially' refers to corporate policy or to state rules. Finally, in the proposed categorisation, ten units of analyses from five interviewees that reflected logic multiplicity, wherein the logics of the state, market, profession, and corporation were present, were found. Five quotes that reflected logic multiplicity but included a (possible) reference to the state logic were excluded from further analyses, leav- ing five quotes that the authors agreed reflected logic multiplicity.

\section{Results}

The analysis identified three logics in the data: the logics of the market, the profession, and the corporation. First, the emergence of each of these logics will be illustrated and explained (4.1). Second, the presence of logic multiplicity and conflicting logics will be analysed and presented (4.2).

\subsection{Institutional logics}

The results illustrated that interviewees justified their safety-related behaviours using various logics. Interviewees' justifications of safety-related behaviours were not only rooted in different institutional orders but also accounted for using arguments that could be linked to the repertoire of elemental categories within these orders [see 7].

\subsubsection{Logic of the market}

Interviewees' rationalisations of safety-related behaviours and decisions reflected the logic of the market. For example, interviewees referred to the system (the NEN Safety Culture ladder) put in place by the public contracting authority [see 39] to promote occupational safety through offering economic advantages. Within this system, organisations can obtain a fictitious discount within public bids if their safety performance meets certain standards. The higher the safety standards, the higher the fictitious discount, thus increasing the chance of winning the bid. Employees use that financial stimulus as a motivation to work safely:

'That [fictitious] discount by [the public contracting authority], it increases our chances, it increases our continuity; loosely translated, it means that I can keep my job. They will not all think like that but..., so that drive is pretty inherent. People have started to think very commercially, to put it bluntly: "we have to do it safely because then we get a discount"" - M20, Higher-level manager

This example exemplifies the logic of the market: safety performance is considered an asset for gaining market share, as better safety performance leads to increased consumer preference. The market logic was also reflected through the focus on increased 
efficiency profit, as rail contractors face heavy competition and are willing to accept the same work for much less than before:

'For example, the contract [area], we accepted that contract for $60 \%$ of the budget we used to get. So, all offerings are brought on the market for about half of their value. And, that really leads to a competition between contractors, which is not good. Because, as foreman, you are responsible for both safety and production. And, that is a balance that you have to keep.' - M10, Foreman

The foreman expresses his worries regarding the negative effects that the competition between contractors has on the balance between safety and production. Albeit implicit, he is worried that the focus on increasing profitability will lead to a focus on production which in turn will result in less safety.

\subsubsection{Logic of the profession}

Inherent to a profession are certain standards, and interviewees described the influence of such standards in their work when it comes to occupational safety. Interviewees stated that they make their own decisions in work and that they use their professional expertise to prioritise safety over conflicting organisational demands:

'Well, you know for yourself that you can perform the work safely. I myself know what I do, and I do it safely. Look, if it really cannot be done, then you will say: "scr*w you"" - M24, Group leader

Interviewees also expressed that they prioritised work over following standard working procedures that are put in place to ensure the safety of employees. Here, quality of craft and personal reputation are associated with 'getting the work done':

'People want to get started with their work. That is it. It is only a waste of time when you are waiting there. [...] But, you know, I would walk to the workplace too. Even if I had more time. Because you can always have a setback you know? And, then, you need that time; you just really need that time' - M31, Group leader

These quotes are reflective of the manner in which professionals use their expert knowledge and ability to make skilled and independent judgements about what is safe and what is not.

\subsubsection{Logic of the corporation}

The institutional logic of the corporation is centred around the organisation's structure with its hierarchical levels. The influence of managers' hierarchical power on safety-related decisions and occupational safety was visible in the data. Managers used their hierarchical power to unburden their subordinates. One of the interviewees described a situation in which his department reached its maximum capacity in terms of occupancy of machinery:

'Well, then I called the director of projects on Friday afternoon and the manager of another one of our branches and I told them: Guys, we have reached our maximum capacity and we are all out. If we have to choose which one of you to cancel this weekend due to sickness of a driver or for some other reason, let's agree that I will call you. My men know that they can call me, and if the moment comes that we have to make decisions, then we can call with the three of us, and we decide on what to do.' - M16, Higherlevel manager

When managers take the responsibility they are entrusted with, they help their employees make safe choices. Employees do not have to deal with higher managers that they do not know and might be more willing to choose safety over the fear of negative consequences. However, managers also used their hierarchical power to determine the content and planning of work by requesting actions from their employees that conflicted with safety but could be beneficial for the market position of the firm:

'I notice sometimes that I ask my employees, what I call "immoral questions". For example, safety is very important, but can't we cancel that safety appointment and focus on our enterprise resource planning?' - M20, Higher-level manager

Although they were aware of the pressure that can follow from their managerial position:

'So, I have to be careful myself, with what I say and the way I say it. Because, if those boys think that they have to do this, have to do that, that things should be completed, then you put a certain pressure on them.' - M4, Foreman

As demonstrated above, examples of rationalisations rooted in the institutional orders of the market, profession, and corporation were apparent in the data. 
Table 2

Safety rationale per institutional logic

\begin{tabular}{lll}
\hline Order & Rationale & Example \\
\hline Market & - Efficiency underlies profitability & 'Yes, but [Name interviewee], later on, it will be about the money, \\
& $\begin{array}{l}\text { - Business practices are determined } \\
\text { by the maximum value possible }\end{array}$ & and then what? Then, do we still talk about safety?' - M17 \\
& rem
\end{tabular}
from transactions

- Self-interest of the client 'But, if there are incidents, unforeseen circumstances, we think that [the client] should take their responsibility. And, they do not, and that's a shame. Fortunately, we are a big company, and we can suffer that, but let's be honest, if you are a smaller company you cannot simply lose 100.000 euro. Then, you end up in a difficult situation.' - M13

\begin{tabular}{|c|c|c|}
\hline Profession & $\begin{array}{l}\text { - Safety is left to the discretion of } \\
\text { the professional who is thought to } \\
\text { have the knowledge and ability to } \\
\text { make skilled independent } \\
\text { judgements of situations } \\
\text { - The organisation structure of the } \\
\text { professional is based on individual } \\
\text { relations } \\
\text { - Sources of authority: professional } \\
\text { association }\end{array}$ & $\begin{array}{l}\text { 'I mean, if they haven't made the proper arrangements, then it's } \\
\text { their bad luck. [... ] Five days later, the same person has not made } \\
\text { the proper arrangements. Then, I say 'Good friend, you had five } \\
\text { days to arrange it, you haven't done so, and now you want me to do } \\
\text { the work illegally." Well, I won't do that.' - M33 }\end{array}$ \\
\hline Corporation & $\begin{array}{l}\text { The informal control mechanism, } \\
\text { the organisation's culture, is } \\
\text { changing }\end{array}$ & $\begin{array}{l}\text { 'And, now, they should come to understand that our management is } \\
\text { now stepping away from it. Previously, they sometimes stated: "You } \\
\text { have to work safely", but they did come to you like: "Can you work } \\
\text { for } 18 \text { hours?" But that is no longer the case. That is done. And, } \\
\text { luckily, you now notice with } 80 \% \text { of the management that that is } \\
\text { over.'- M17 } \\
\text { '[Name former manager] did not have such a stance. He was more } \\
\text { like "Yes, that is your problem", something like that, along those } \\
\text { lines. He thought safety to be important, but he directed a lot of } \\
\text { ownership to everyone. And, fortunately, [name current manager] is } \\
\text { a manager who says: "Okay, that is my problem, we will solve that } \\
\text { together"'-M20 }\end{array}$ \\
\hline
\end{tabular}

Table 2 provides more examples of such rationalisations.

\subsection{Logic multiplicity}

The previous section already demonstrated that multiple logics are core to occupational safety. In addition to these examples, which each reflect a single logic, examples that reflected complexity that arose when incompatible prescriptions from multiple institutional logics were encountered also emerged in the data. Examples of complexity between the institutional orders of the market, profession, and corporation were present (see Fig. 1). Within each quote, the part referring to a particular logic is underlined. Words or sentences referring to the market logic are underlined with a thick line, those referring to the profession logic are underlined with a dotted line, and those words and sentences referring to the corporation logic are double underlined.

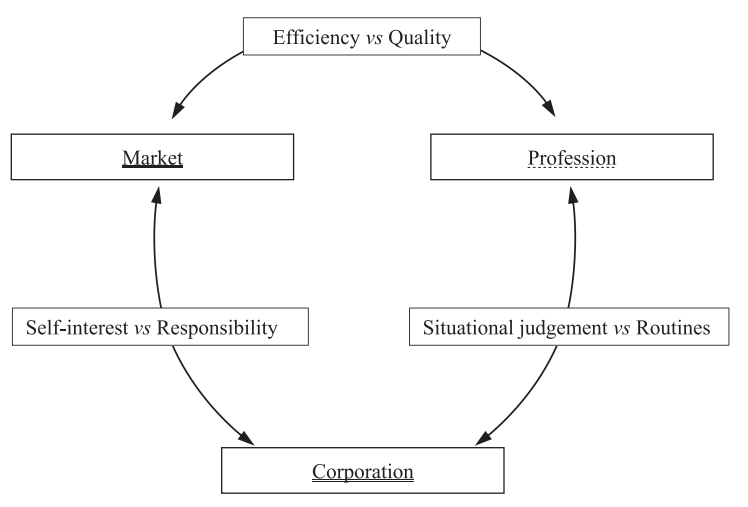

Fig. 1. The institutional orders of the market, profession and corporation and the complexities arising from incompatible prescriptions between them.

\subsubsection{Logic of the market versus logic of the profession}

When the orders of the market and the profession collide, actors face the market logic's self-interested focus on increasing (efficiency) profits and the 
profession logic's focus on delivering high-quality work and personal expertise.

'This year, we have cancelled our bids three times. [Researcher: Yes, but I assume there are just so many times you can cancel your bids on work?] [... ] Even if we have to do it a hundred times, that does not matter. I will not make concessions to work when the electricity is running. I just do not. Very simple; we simply do not. And, that is also something that the customer has to learn. And, if that means that our organisation does not have any work in the Netherlands for a while, but you have to be able to explain it as management.' - M12, Higher-level manager

In the above quote, the professional is not willing to make concessions to working safely. Based on his knowledge, he judges that working when electricity is running is unsafe, despite the apparent wish of the client. The interviewee in this example solves the complexity arising from the collision of the logic of the market and the logic of the profession by stating that the client (market) has to learn that the professional will not make concessions to working safely. He implicitly stresses the legitimacy of his choice based on his expert knowledge about work safety.

\subsubsection{Logic of the market versus logic of the corporation}

When the market logic collides with the logic of the corporation, actors face the market's self-interested

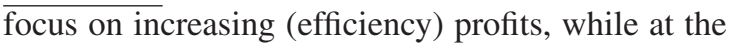
same time, they have to uphold their status in the managerial hierarchy and their bureaucratic roles, and they must think about the market position of the firm:

'A few years ago, we sometimes thought we just bid on a work and then we will see what happens; we pressure the customer; it is his problem. Well, the customer responded "you have accepted the job, it is your problem". [... ] I am responsible for the people that work here; well, a safe workplace must be present; we must have validated that in the tender phase. If not, we are going to question it, and if that question is answered unsatisfactorily, we will not make a bid on that work.'

- M12, Higher-level manager

The interviewee describes that initially, he was more motivated by increasing efficiency, but when confronted with the self-interest of the client reasoning from the same market logic, he turned to the corporation logic and took responsibility for his subordinates. This example illustrates that the interviewee tried to solve the complexity initially by leaving things implicit, reckoning that the client would take responsibility. However, when the safety question was made more explicit, complexity arose, and in this instance, the parties involved were forced to settle the responsibility question. As the client refused to pick up the glove, the interviewee was almost forced to do so.

\subsubsection{Logic of the profession versus logic of the corporation}

When the order of the profession collides with the order of the corporation, actors are confronted with the managerial hierarchy and the organisational culture (corporation logic) on one hand and personal expertise and reputation (profession logic) on the other:

'Well, we solve a lot of things ourselves here, and that is something we shouldn't do. You try to have a solution-focussed stance, and sometimes you do things that are not possible. And, when you don't do [solve] them, you are a dick, but if you do [solve] them and something happens, you are screwed. And, those are seem$\overline{\overline{\text { ingly very small things, }}}$ but they can have far-reaching consequences' - M24, Group leader

The interviewee describes that - following from the logic of the profession - there is a certain willingness to get the work done, which is also expected from them. However, getting the work done requires professionals to use their expert knowledge to make a translation from the general applicable rules and routines of the corporation to an approach that fits with the specific situation. In the process of doing so, they are likely to deviate from and violate those corporate routines, and inherently the corporation logic. Making this translation is accepted - and perhaps even expected by managers - but only as long as things go well. When things go wrong, managers will use their hierarchical power to protect themselves, hiding behind corporate routines that should have been followed.

\section{Discussion}

The aim of this study was to increase our understanding of what drives safety-related decisions and 
behaviours. We proposed that the discourse of institutional logics could be used as a lens to uncover, illustrate, and explain rationales for safety-related behaviours and decisions that are otherwise left uncovered or dismissed as irrational [cf. 4, 25, 26].

This study makes several contributions to the field of occupational safety. First, it demonstrates that an institutional logics perspective can be effectively applied to empirical data and used to uncover and identify the easily overlooked differences between the rationales that people employ to justify their views about occupational safety. By applying the institutional logics perspective to the descriptions of safety issues by managers, we were able to uncover the logics of the market, profession, and corporation. Within this study, the market logic was reflected in the use of safety performance as a means to increase consumer preference and the effects of market competitiveness on safety. The professional logic led managers to prioritise staying safe over getting the work done, whereas others prioritised the timely completion of work over standard operating procedures that should keep them free from harm. The logic of the corporation was reflected in the means in which managers made use of their hierarchical power to determine the content and planning of work. These examples demonstrate that an institutional logics perspective can be used to identify different rationalities underlying behaviours and decisions and how those different logics lead to differences in approaches towards safety.

Second, in addition to illustrations of individual institutional logics in the data, examples of logic multiplicity between the logics of the market, profession and corporation emerged. Here, people use the same words but speak different languages. Complexity between the logics of the market and the profession arose due to the incompatibility of the market logic's self-interested focus on increasing (efficiency) profits, whereas the professional wanted to adhere to high-quality work standards. In this situation, the manager resolved the conflict by stating the client had to learn from the professional's personal expertise regarding how to keep the work safe. The complexity between the logics of the market and the corporation occurred as result of the market logic's self-interested focus on increasing (efficiency) profits, whereas managers have to uphold their hierarchical status and responsibilities. Initially, the solution to complexity was sought in leaving the responsibility for occupational safety implicit. However, when the client made this issue explicit and refused to take responsibility, the manager was forced to do so. The complexity between the logics of profession and the corporation arose as a result of rules and routines that are prescribed by the corporation that were incompatible with the work that was expected to be done. The group lead tried to solve the complexity by using his expert knowledge to translate the general rules and routines to fit with the specific situation.

The new concepts (i.e., the various logics and their associated elemental categories) introduced by the institutional logics framework provide both researchers and practitioners with a discourse that allows them to study and analyse occupational safety in new manners. These concepts not only allow for providing meaning to seemingly irrational behaviours [4], but also provides a means to break down the complex structure of behaviours rooted in various rationales into manageable pieces [cf. 22-24]. Additionally, these concepts complement the local rationality principle that Dekker [8] introduced to explain human error and further it by illustrating that similar people in similar situations can reach different conclusions based on the prevailing institutional logic [22].

Third, the framework designed Besharov and Smith [15] proved to be a useful tool to indicate the degree of conflict within the organisation. As multiple logics were core to the safety-related decisions and behaviours (i.e., a high degree of logic centrality) and provided contradictory prescriptions for action (i.e., a low degree of logic compatibility), the organisation in this study can be categorised as a contested organisation. In line with the results, this implies that members of the organisation 'hold competing expectations about appropriate organisational goals and lacking a clear guideline as to which goals should prevail' and that the organisation encounters extensive conflict [15, p371]. The contradictory prescriptions for action and the resulting competition between organisational goals jeopardises occupational safety. If safety is not beyond a doubt the number one organisational goal, employees cannot be expected to maintain workplace safety at all times. The ability to predict the degree of conflict within an organisation and to understand how this conflict originates provides managers with opportunities to minimise such conflict and its impact on performance and stability $[15,40]$.

In sum, the demonstrated usability of the institutional logics perspective in studying and analysing occupational safety provides both researchers and practitioners with new means to explore and address human and organisational safety issues. 
The demonstrated usability of an institutional logics perspective for occupational safety also has implications for practice. First, managers should be aware that people can have different underlying rationales for their safety-related thinking, decisions and behaviours. Second, in addition to this awareness, the ability to identify the different logics at play allows managers and safety professionals to minimise the impact of speed on accuracy in times of haste and crisis. Third, through awareness and identification of the different logics, managers and safety professionals can help in exploring misunderstandings in conversations between different actors, in addition to uncovering the nature of these misunderstandings through articulating the various logics. Fourth, the discourse of logics can be used in the analysis of occupational safety incidents. As Dekker [8] notes, no one comes to work to do a bad job, and what they do and decide makes sense to them in that specific situation. In the case of a safety incident, the institutional logics perspective can shed light on the motivations and rationales that drove employee decisions and behaviours instead of dismissing the accident solely as caused by human failure. Finally, the discourse of logics provides (safety) managers with the ability to recognise, articulate, and discuss the different rationales for occupational safety that are easily overlooked by traditional management approaches. In doing so, it not only contributes to the understanding of employee functioning in terms of occupational safety but also provides managers with opportunities to engage with employees by articulating the divergent rationales they apply and to use the discourse of logics by adapting their arguments in such a manner that they are in line with the dominant logic of their conversation partners, thus increasing their intelligibility and persuasiveness.

Although we are convinced that the findings presented in this study contribute to the current knowledge and understanding of safety-related decisions and behaviours, there are some limitations that must be addressed. First, the group of managers participating in this study was limited in size, especially considering the limited number of managers that made implicit references to institutional logics. Future research should therefore further explore the presence of (conflicting) institutional logics concerning occupational safety with larger research samples and in organisations operating in other sectors. Second, although the state logic seemed to emerge from the data, it proved difficult to unequivocally interpret these units of analyses. The wordings used by inter- viewees did not clearly allow for a definite answer regarding the origins of the referenced rules (i.e., state or corporation), which led us to adopt a rather conservative approach and exclude all related quotes. Future research should therefore explore whether references to the state logic can be interpreted more clearly.

\section{Conclusion}

The current study demonstrated that the institutional logics perspective is a valuable lens that provides new methods to uncover, study, and explain the different rationales underlying occupational safety. It allowed us to uncover the logics of the market, profession and corporation in occupational safety-related thinking, decisions and behaviours of managers. Such insights into and understanding of the various rationales underlying safety can help in the prevention and analysis of accidents, ultimately leading to safer workplaces.

\section{Acknowledgments}

This research was approved by the ethical committee of the Faculty of Behavioural, Management and Social sciences of the University of Twente (reference number: BCE16359). This research did not receive any specific grant from funding agencies in the public, commercial, or not-for-profit sectors.

\section{Conflict of interest}

None to report.

\section{References}

[1] Beltran SL, Vilela RAG, de Almeida IM. Challenging the immediate causes: A work accident investigation in an oil refinery using organizational analysis. Work. 2018;59:61736. doi:10.3233/WOR-182702

[2] Nowrouzi-Kia B, Gohar B, Casole J, Chidu C, Dumond J, McDougall A, Nowrouzi-Kia B. A systematic review of lost-time injuries in the global mining industry. Work. 2018;60:49-61. doi: 10.3233/WOR-182715

[3] International Labour Organisation. Safety and health at work. Available from: http://www.ilo.org/global/topics/ safety-and-health-at-work/lang-en/index.htm [Accessed 15th July 2018]

[4] Hopkins A. For whom does safety pay? The case of major accidents. Safety Science. 1999;32(2-3):143-53. doi: 10.1016/S0925-7535(99)00017-X 
[5] Friedland R, Alford RR. Bringing society back in: Symbols, practices and institutional contradictions. In: Powel WW, DiMaggio PJ. (eds.) The new institutionalism in organizational analysis. Chicago, IL: University of Chicago Press; 1991. pp. 232-67.

[6] Greenwood R, Raynard M, Kodeih F, Micelotta ER, Lounsbury M. Institutional complexity and organizational responses. The Academy of Management Annals. 2011;5(1):317-71. doi: 10.1080/19416520.2011.590299

[7] Thornton PH, Ocasio W, Lounsbury M. The institutional logics perspective: A new approach to culture, structure, and process. Oxford: Oxford University Press; 2013.

[8] Dekker SWA. Accidents are normal and human error does not exist: A new look at the creation of occupational safety. International Journal of Occupational Safety and Ergonomics. 2003;9(2):211-18. doi: 10.1080/10803548.2003.11076564

[9] Thornton PH, Ocasio W. Institutional logics. In Greenwood R, Oliver C, Suddaby R, Sahlin-Andersson K. (eds.), The SAGE Handbook of Organizational Institutionalism. London: Sage; 2008. pp. 99-129.

[10] Thornton PH, Ocasio W. Institutional logics and the historical contingency of power in organizations: Executive succession in the higher education publishing industry, 1958-1990. American Journal of Sociology. 1999;15(3):801-43. doi: 10.1086/210361

[11] Johansen CB, Waldorff SB. What are institutional logics - And where is the perspective taking us? In: Krücken G, Mazza C, Meyer RE, Walgenbach P. (eds.) New Themes in Institutional Analysis - Topics and Issues from European Research. Cheltenham, UK: Edward Elgar Publishing Limited. 2017. pp. 51-76.

[12] Waldorff SB, Reay T, Goodrick E. A tale of two countries: How different constellations of logics impact action. In Lounsbury M, Boxenbaum E. (eds.) Institutional logics in action, Part A. 2013. pp. 99-129.

[13] Fairclough S, Micelotta ER. Beyond the family firm: Reasserting the influence of the family institutional logic across organizations. In Lounsbury M, Boxenbaum E. (eds.) Institutional logics in Action, Part B. 2013. pp. 63-89.

[14] Greenwood R, Díaz AM, Li SX, Lorente JC. The Multiplicity of Institutional Logics and the Heterogeneity of Organizational Responses. Organization Science. 2010;21(2):521-39. doi: 10.1287/orsc.1090.0453

[15] Besharov ML, Smith WK. Multiple institutional logics in organizations: Explaining their varied nature and implications. Academy of Management Review. 2014;39(3):364-81. doi: 10.5465/amr.2011.0431

[16] Meyer JW, Rowan B. Institutionalized organizations: Formal structure as myth and ceremony. American Journal of Sociology. 1977;83(2):340-63. doi: 10.1086/226550

[17] Perkmann M, McKelvey M, Philips N. Protecting scientists from Gordon Gekko: How organizations use hybrid spaces to engage with multiple institutional logics. Organization Science. 2019;30(2):298-318. doi: 10.1287/orsc.2018.1228

[18] Schwartz B, Scharpe K. Practical Wisdom: The right way to do the right thing. London, UK: Penguin; 2010.

[19] Nicolini D, Delmestri G, Goodrick E, Reay T, Lindberg K, Adolfsson P. Look what's back! Institutional complexity, reversibility and the knotting of logics. British Journal of Management. 2016;27:228-48. doi: 10.1111/14678551.12156

[20] Daudigeos T, Boutinot A, Jaumier S. Taking stock of institutional complexity: Anchoring a pool of institutional logics into the interinstitutional system with a descen- dent hierarchical analysis. In Lounsbury M, Boxenbaum E. (eds.) Institutional logics in Action, Part B. 2013. pp. 319350.

[21] Madsen CU, Hasle P. Commitment or compliance? Institutional logics of work environment management. Nordic Journal of Working Life Studies. 2017;7:17-38. doi: 10.18291/njwls.v7iS2.96688

[22] Jia YA, Rowlinson SM, Loosemore M, Xu M, Li B, Gibb A. Institutions and institutional logics in construction safety management: The case of climatic heat stress. Construction Management and Economics. 2017;35(6):338-367. doi: 10.1080/01446193.2017.1296171

[23] Rocha RS. Institutional effects on occupational health and safety management systems. Human Factors and Ergonomics in Manufacturing \& Service Industries. 2010;20(3):211-25. doi: 10.1002/hfm.20176

[24] Lingard H, Oswald D, Le T. Embedding occupational health and safety in the procurement and management of infrastructure projects: Institutional logics at play in the context of new public management. Construction Management and Economics. 2019:1-17. doi: 10.1080/01446193.2018.1551617

[25] Swuste P, Van Gulijk C, Zwaard W. Safety metaphors and theories, a review of the occupational safety literature of the US, UK and The Netherlands, till the first part of the 20th century. Safety Science. 2010;48:1000-18. doi: 10.1016/j.ssci.2010.01.020

[26] Reader TW, O'Connor P. The Deepwater Horizon explosion: Non-technical skills, safety culture, and system complexity. Journal of Risk Research. 2013;17(3):405-24. doi: 10.1080/13669877.2013.815652

[27] Reay T, Jaskiewicz P, Hinings CR. How family, business, and community logics shape family firm behavior and "rules of the game" in an organizational field. Family Business Review. 2015;28(4):292-311. doi: $10.1177 / 0894486515577513$

[28] Glynn MA, Lounsbury M. From the critics' corner: Logic blending, discursive change and authenticity in a cultural production system. Journal of Management Studies. 2005;42(5):1031-55. doi: 10.1111/j.14676486.2005.00531.x

[29] Thornton PH. The rise of the corporation in a craft industry: Conflict and conformity in institutional logics. The Academy of Management Journal. 2002;45(1):81-101. doi: $10.2307 / 3069286$

[30] Jones C. Livne-Tarandach R, Balachandra L. Rhetoric that wins clients: Entrepreneurial firms use of institutional logics when competing for resources. Institutions and Entrepreneurship. 2010;21:183-218. doi: 10.1108/S02772833(2010)0000021011

[31] Pahnke EC, Katila R, Eisenhardt KM. Who takes you to the dance? How partners' institutional logics influence innovation in young firms. Administrative Science Quarterly. 2015;60(4):569-633. doi: 10.1177/0001839215592913

[32] Bhappu AD. The Japanese family: An institutional logic for Japanese corporate networks and Japanese management. Academy of Management Review. 2000;25(2): 409-15.

[33] Ingram P, Rao H. Store wars: The enactment and repeal of anti-chain-store legislation in America. American Journal of Sociology. 2004;110(2):446-87. doi: 10.1086/422928

[34] Ingram P, Yue LQ, Rao H. Trouble in store: Probes, protests, and store openings by Wal-Mart, 1998-2007. American Journal of Sociology. 2010;116(1):53-92. doi: $10.1086 / 653596$ 
[35] Friedland R. Religious Nationalism and the Problem of Collective Representation. Annual Review of Sociology. 2001;27:125-152. doi: 10.1146/annurev.soc.27.1.125

[36] Friedland R. Money, sex, and god: The erotic logic of religious nationalism. Sociological Theory. 2002;20(3):381425. doi: 10.1111/0735-2751.00169

[37] Michael JH, Guo ZH, Wiedenbeck JK, Ray CD. Production supervisor impacts on subordinates' safety outcomes: An investigation of leader-member exchange and safety communication. Journal of Safety Research. 2006;37(5):469-77. doi: 10.1016/j.jsr.2006.06.004
[38] Reay T, Jones C. Qualitatively capturing institutional logics. Strategic Organization. 2016;14(4):1-14. doi: $10.1177 / 1476127015589981$

[39] NEN. Safety Culture Ladder. Available from: http://www. veiligheidsladder.org/en [Accessed $20^{\text {th }}$ April 2019].

[40] Matinheikki J, Aaltonen K, Walker D. Politics, public servants, and profits: Institutional complexity and temporary hybridization in a public infrastructure alliance project. International Journal of Project Management. 2019;37:298317. doi: 10.1016/j.ijproman.2018.07.004 